\title{
Estimation of the brain and spinal cord conduction time in man by means of the somatosensory evoked potentials and $\mathrm{F}$ and $\mathrm{H}$ responses
}

\author{
J S I I V O L A
}

From the Department of Neurology and Clinical Neurophysiology, Oulu University Central Hospital, Oulu, Finland

SU M M A R Y Somatosensory evoked potential (SSEP) recordings from the scalp were performed in 17 healthy subjects. In seven of these SSEP was also recorded at the level of the second lumbar spine. In the other ten $F$ and $H$ responses and the corresponding $M$ responses were studied. By means of the SSEP recordings at the level of the second lumbar spine and the F- and H-responses, the conduction time in the brain and spinal cord, that is central latency, was calculated and the following results were obtained: $16.0 \mathrm{~ms}$ with standard deviation (SD) $\pm 1 \cdot 1 \mathrm{~ms}$ (by means of SSEPs), $9.5 \pm 2.4 \mathrm{~ms}$ (by means of $F$ response) and $13.1 \pm 1.5 \mathrm{~ms}$ (by means of $\mathrm{H}$ response). Of the three methods used the $\mathrm{H}$ response method seems to be the best for clinical purposes: it is easy to perform and statistically it is more stable than the $F$ response recording; moreover the recording can be performed reliably even in persons with thick back muscles and subcutaneous fat, unlike the evoked potential procedure which only with difficulty shows detectable responses at the lumbosacral levels in such persons. Three patients are presented to illustrate the technique; in one of these the recording evoked potentials from the epidural space were recorded.

Electroneuromyography of the peripheral nervous system occupies an important position in clinical neurodiagnostis. However, for study at various levels of the spinal cord and brain it is less valuable. During the last few years somatosensory evoked potential (SSEP) recordings have improved the diagnostic approach to the spinal cord and brain: it is now possible to record scalp potentials evoked by stimulation of the tibial or peroneal nerves. ${ }^{1-4}$

In order to distinguish peripheral lesions from these at a higher level, that is in the spinal cord and brain, spinal SSEP recordings have now made it possible to differentiate conduction time at the root and peripheral nerve levels. Techniques available to perform the latter include surface recordings, ${ }^{35-7}$ and, with their better signal/noise ratio, epidural $^{8-10}$ and subdural ${ }^{11-15}$ recordings. Dorf-

Address for reprint requests: Dr J Siivola, Oulu University Hospital SF-90220 Oulu 22, Finland.

Accepted 6 August 1980 $\operatorname{man}^{4}$ has introduced a method to calculate the peripheral nerve and root conduction time by means of $F$ response. In 1956 Dawson and Merton $^{16}$ suggested that this $F$ response was due to "recurrent" discharges from motoneurones activated antidromically. This suggestion has gained support from other investigators. ${ }^{17}{ }^{18}$ However, it is known that the recognition of $F$ response and the determination of latency to onset of $F$ response may sometimes be difficult; it may vary in different persons and even in the same subject in different times of examination. ${ }^{19}$ In the proximal part of the sciatic nerve and roots the conduction velocity may be calculated also by means of Hoffman's (H) response, ${ }^{20}$ and the $\mathrm{H}$ response is easy to detect in clinical practice.

In this study three recording methods were used for the measurement of the conduction times at the peripheral levels (roots and peripheral nerve):

(1) the somatosensory evoked potentials from the region of the second lumbar spine, (2) F response, 
and (3) $\mathrm{H}$ response. From the measurements obtained, and from scalp somatosensory responses, the conduction time in the brain and spinal cord has been calculated.

\section{Material and methods}

Equipment During the recordings the subjects were supine and were instructed to minimise voluntary movements and swallowing. The recordings were carried out with routine EEG electrodes on the scalp and with chlorided silver cup electrodes of $9 \mathrm{~mm}$ diameter on the body. The signals were led first through a high impedance differential amplifier with bandpass of $20 \mathrm{~Hz}-0.5 \mathrm{kHz}$ into an EMG-machine (Disa $14 \mathrm{C} \mathrm{12}$ ) and from there into a two-channelled signal analyser, HP-5481 A, in which the analysis of both recordings was possible simultaneously. The resolution of sampling (binwith) was $200 \mu \mathrm{s}$. Single stimuli were produced with the stimulator (Disa $3 \mathrm{~K} \mathrm{62}$ ) at a rate of four per second, square wave pulses, duration $0.3 \mathrm{~ms}$. The stimulation sites were popliteal fossa or ankle (peroneal or tibial nerve) or both. Stimulus intensity was adjusted in order to produce a slight twitching of the foot. The averaging of 512 responses was carried out from the scalp, recording site $2.5 \mathrm{~cm}$ behind the vertex with the reference electrode on the mid-forehead (Fz: 10-20 EEG system). The $\mathrm{H}$ responses were measured with the routine method applied for clinical purposes: the latency was measured to the beginning of the maximal $\mathrm{H}$ response during the stimulation of the tibial nerve from popliteal fossa, recorded from the surface of the soleus muscle; the reference electrode $20 \mathrm{~mm}$ distally from the proximal one. The latency measurement of $F$ response was also performed to the beginning of the maximal $F$ wave. In SSEP-recordings of the second lumbar spine the latency measurement was performed at the peak of response, since the peak was the clearest and most reliable indicator of latency.

In order to calculate the conduction time of the central nervous system in the brain and spinal cord, that is "central latency," the measurements of conduction time of the peripheral nervous system were performed with three different methods: in seven subjects by means of evoked potentials from the level of the second lumbar spine with surface recordings, in ten by means of both $\mathrm{H}$ response and also $\mathrm{F}$ response.

Approach I In seven healthy subjects, aged 15 to 34 years, body length from $165 \mathrm{~cm}$ to $178 \mathrm{~cm}$, stimulation of the peroneal nerve was performed separately from the popliteal fossa of both legs.
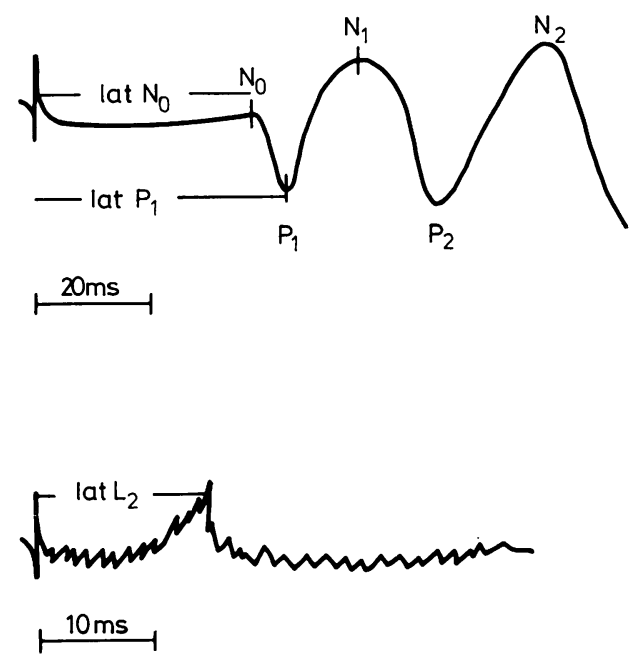

Fig 1 Diagram of the somatosensory evoked response at the level of the scalp and second lumbar spine induced by stimulation of the peroneal nerve in the popliteal fossa (A pproach I). Upper tract: scalp response, latency measurements to the onset of response $(\mathrm{No})$ and to the peak $(\mathrm{Pl})$ of the first positive deflection. No-P1-N1 is component $I^{2}$ Lower tract: evoked response recorded from the second lumbar spine with surface electrodes.

Recordings were taken with surface electrodes simultaneously from the scalp and also from the second lumbar spine. (Recordings from the inion were also carried out, but their signal/noise ratio was low and therefore they were not included in the present results.) Latency measurements were carried out at the onset of the scalp response (lat No), also at the peak P1 (lat P1), that is the positive peak of component $I,{ }^{2}$ and also the peak of negative deflection of the evoked response at the level of the second lumbar spine (lat L2). Figure 1 shows the typical configurations and the important landmarks of the responses in Approach I.

The conduction velocity of the sciatic trunk between the popliteal fossa and the second lumbar spine also was calculated. This conduction velocity $(\mathrm{CVs})$ may be formulated:

(a) $\mathrm{CV}_{\mathrm{s}}=\mathrm{d} /$ lat $\mathrm{L} 2$ where $\mathrm{d}=$ distance between the popliteal fossa and the second lumbar spine ( $\mathrm{mm}$ ).

The conduction time at the level of brain and spinal cord, central latency (CLs), may be presented as the formula:

(b) $\mathrm{CLs}_{\mathrm{s}}=$ lat No-lat L2.

Also the ratio of CLs and body length (B1) was 
calculated. This ratio (CLIs) is formulated as:

(c) $\mathrm{CLI}_{\mathrm{s}}=\mathrm{CLs} / \mathrm{B} 1$.

Approach II Ten volunteers, six males and four females aged 22 to 47 years, (body length from 154 to $199 \mathrm{~cm}$ ), were studied by stimulation of the tibial nerve at the ankles of both legs. Recording from the scalp was taken as in Approach I: the latency was measured at the onset of the response (lat No) and at the positive peak P1. The latencies of $\mathrm{F}$ responses from both legs were measured at the beginning of the maximal $F$ response (lat $F$ ) and at the one of the corresponding maximal muscle (M) response (lat $\mathbf{M}$ ). The schematic representations of the scalp and $F$ response are presented in fig 2.

The conduction time of the tibial nerve and the sciatic trunk $\left(C T_{r}\right)$ was calculated with the method presented by Dorfman, ${ }^{4}$ which may be formulated as:

(d) $\mathrm{CT}_{\mathrm{F}}=\frac{\text { lat } \mathrm{F}-\text { lat } \mathrm{M}-1}{2}$ (ms)

1 (ms)=the central delay of the spinal cord, proposed by Dorfman. ${ }^{4}$ Further, the conduction time

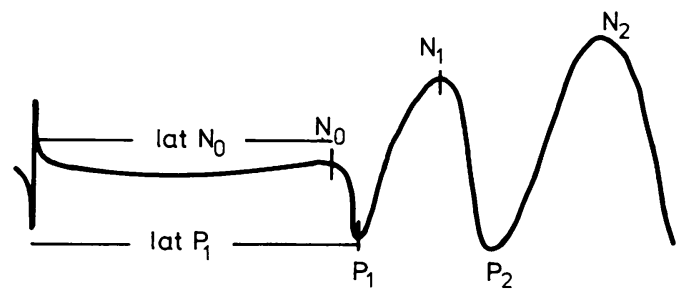
$20 \mathrm{~ms}$

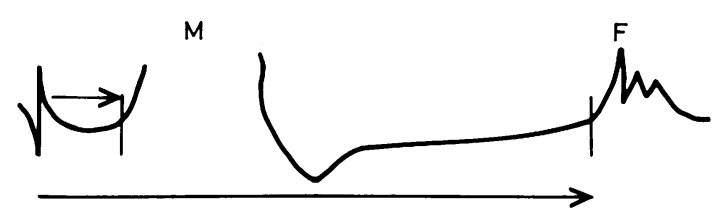

$$
\stackrel{10 \mathrm{~ms}}{\longmapsto}
$$

Fig 2 Diagram of the scalp and $F$ response, with the corresponding $M$ response, induced by stimulation of tibial nerve at the ankle (Approach II). Upper tract: scalp response, latency measurements to the onset of response $(\mathrm{No})$ and to the peak $(\mathrm{Pl})$ of the first positive deflection. No-P1-N1 is component $I$. Lower tract: $F$ response with the corresponding $M$ response; latency measurements were performed to the onset of $F$ and $M$ responses. at the level of brain and spinal cord, the central latency $\left(\mathrm{CLF}_{\mathrm{F}}\right)$ may be presented as the formula:

(e) $\mathrm{CLF}_{\mathrm{F}}=$ lat $\mathrm{No}-\left(\frac{\text { lat } \mathrm{F}-\text { lat } \mathrm{M}-1}{2}\right)(\mathrm{ms})$.

The value of, $C_{F}$ was calculated in all the ten controls and was also compared to the body length (B1). This central latency index $\left(\mathrm{CLI}_{F}\right)$ may be formulated as:

(f) $\mathrm{CLI}_{F}=\mathrm{CLF} / \mathrm{B} 1(\mathrm{~ms} / \mathrm{m})$.

Approach III In the same controls as presented in Approach II, stimulation of the tibial nerve in the popliteal was performed separately on both legs. The recording site on the scalp was the same as in Approaches I and II. The latency was measured at the onset of the response, lat No, and at peak $\mathrm{P} 1$, lat $\mathrm{P} 1$. $\mathrm{H}$ responses from the soleus muscles on both legs were studied, and latencies were measured at the onset of the maximal $H$ response (lat $\mathrm{H})$ and the corresponding maximal $\mathbf{M}$ response (lat $\mathbf{M})$. The schematic representations of the scalp and $\mathrm{H}$ responses are presented in fig 3 . The method of averaging the conduction time $\left(\mathrm{CT}_{\mathrm{H}}\right)$ and the conduction velocity $\left(\mathrm{CV}_{\mathrm{H}}\right)$ of
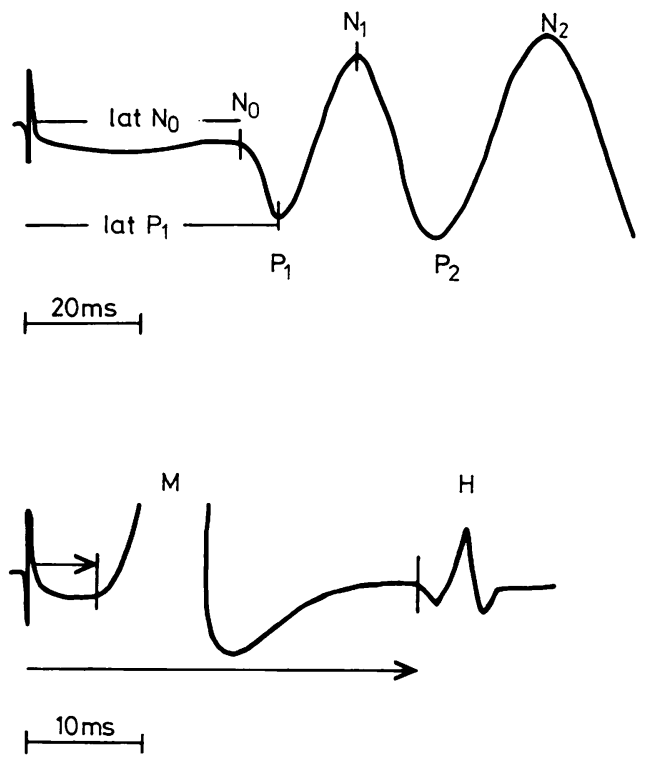

Fig 3 Diagram of the scalp and $H$ response with the corresponding $M$ response induced by stimulation of tibial nerve in the popliteal fossa (A pproach III). Upper tract: scalp response, latency measurements to the onset of response (No) and to the peak (PI) of the first positive deflection. Part of response, No-P1-N1, is component $1 .{ }^{2}$ Lower tract: $H$ response with the corresponding $M$ response; latency measurements were performed to the onset of $H$ and $M$ responses. 
the sciatic trunk (between popliteal fossa and spinal cord) has been formulated as follows ${ }^{20}$ :

(g) $\mathrm{CT}_{\mathrm{H}}=\frac{\text { lat } \mathrm{H}-\text { lat } \mathrm{M}-1}{2}$ (ms)

(h) $\mathrm{CV}_{\mathrm{H}}=\frac{80 \% \times \text { body length }(\mathrm{B} 1)}{\text { lat } \mathrm{H}-\text { lat } \mathrm{M}-1}(\mathrm{~m} / \mathrm{s})$

$1 \mathrm{~ms}=$ the monosynaptic delay of the spinal cord, a time estimated from studies in animals ${ }^{21}$ and in man. ${ }^{11}$ The figure $80 \%$ is based on examinations of cadavers. ${ }^{22}$ The formula (h) expresses the average conduction velocity of the afferent and efferent neural pathways of the sciatic trunk.

The conduction time at the level of brain and spinal cord, that is the central latency $\left(\mathrm{CL}_{H}\right)$, was also calculated in these 10 controls; it may be formulated as follows:

(i) $\mathrm{CL}_{\mathrm{H}}=$ lat $\mathrm{No}-\left(\frac{\text { lat } \mathrm{H}-\text { lat } \mathrm{M}-1}{2}\right)$ (ms).

Further, the $\mathrm{CL}_{\mathrm{H}}$ was compared to the body length of the controls and this value, the central latency index $\left(\mathrm{CLI}_{\mathbf{H}}\right)$, may be formulated as:

(j) $\mathrm{CL}_{\mathrm{H}}=\mathrm{CL} / \mathrm{B} 1(\mathrm{~ms} / \mathrm{m})$.

Student's $t$ test for paired observations was used for statistical evaluation of the differences between $\mathrm{CL}_{F}$ and $\mathrm{CL}_{\mathbf{H}}$ values in Approaches II and III.

Patient studies Case 1, a 30-year-old male, who had earlier been healthy but who had sustained acute trauma to the back about two months preceding the examination showed symptoms typical of radicular lesion of lumbosacral roots, especially on the right leg. Stimulation of the tibial nerve was performed separately on both legs from the popliteal fossa; 512 responses were recorded from the scalp and their averages taken. By means of $\mathbf{H}$ response and the corresponding $M$ response the conduction velocity, $\mathrm{CV}_{\mathrm{H}}$, was calculated for both sides. Thereafter stimulation of the tibial nerve from the popliteal fossa was performed and the evoked responses with surface electrodes were recorded from the second lumbar spine, the reference being on the forehead. 256 responses were averaged. Recordings of evoked responses were then carried out at the level of the third lumbar segment, between the third and fourth lumbar spine, with a platinum iridium wire electrode of $0.2 \mathrm{~mm}$ diameter placed in the epidural space using the technique presented by Shimoji et al. ${ }^{9}$ The reference electrode, also a platinum iridium wire, was inserted into subcutaneous tissue (depth about $\frac{1}{2} \mathrm{~cm}$ ) in the region of the right upper gluteal area. The stimulation of the tibial nerve was performed separately on both legs from the popliteal fossa, and 256 responses were averaged.

Case 2, a 38-year-old male with Hodgkins' disease who had suddenly suffered from acute paraplegia; myelography showed extradural metastasis at the level of the sixth to tenth thoracic segments, the CSF space being totally obliterated. Stimulation was performed from the tibial nerve at the level of popliteal fossa and recording was taken from the scalp. Conduction velocity, $\mathrm{CV}_{\mathrm{H}}$, was calculated for both sides. Recordings from the scalp and the seventh cervical segment were also taken after stimulation of the median nerve from the wrist, separately in both hands (for details, see Siivola et al. ${ }^{23}$ )

Case 3, a 30-year-old male with multiple sclerosis (MS) had muscle weakness and sensory deficits mainly in the right limbs, especially on the right leg. Stimulation of the tibial nerve from the popliteal fossa separately on both sides was performed and recording taken from the scalp. The conduction velocity, $\mathrm{CV}_{\mathrm{H}}$, was calculated by means of $\mathrm{H}$ response from both sides.

\section{Results}

The main results are presented in tables 1,2 , and 3.

Table 1 The measured and calculated values of Approach 1

\begin{tabular}{|c|c|c|c|c|c|c|c|c|}
\hline & $\begin{array}{l}\text { lat No } \\
\text { (ms) }\end{array}$ & $\begin{array}{l}\text { lat } N o / B I \\
(m s / m)\end{array}$ & $\begin{array}{l}\text { lat } P I \\
(m s)\end{array}$ & $\begin{array}{l}\text { lat } L_{2} \\
(\mathrm{~ms})\end{array}$ & $\begin{array}{l}C V_{S} \\
(m / s)\end{array}$ & $\begin{array}{c}C L_{S} \\
(m s)\end{array}$ & $\begin{array}{l}C L I_{S} \\
(m s / m)\end{array}$ & $\begin{array}{l}A-P_{1} / N_{1} \\
(\mu V)\end{array}$ \\
\hline $\begin{array}{l}\text { Mean } \\
\text { SD } \\
\mathbf{N}\end{array}$ & $\begin{array}{c}29 \cdot 2 \\
1 \cdot 1 \\
7\end{array}$ & $\begin{array}{c}17 \cdot 1 \\
0.9 \\
7\end{array}$ & $\begin{array}{c}33 \cdot 4 \\
2 \cdot 5 \\
7\end{array}$ & $\begin{array}{c}13.3 \\
0.6 \\
7\end{array}$ & $\begin{array}{c}55 \cdot 0 \\
3 \cdot 8 \\
7\end{array}$ & $\begin{array}{c}16 \cdot 0 \\
1 \cdot 1 \\
7\end{array}$ & $\begin{array}{l}9 \cdot 3 \\
0 \cdot 7 \\
7\end{array}$ & $\begin{array}{l}1 \cdot 3 \\
0 \cdot 4 \\
7\end{array}$ \\
\hline
\end{tabular}

lat No=latency to the onset of scalp response

lat $\mathrm{No} / \mathrm{Bl}=$ lat $\mathrm{No}$ compared to the body length $(\mathrm{Bl})$ of controls

lat P1 = latency to the peak P1 of scalp response

lat L2 =latency to the peak of evoked response at the level of the second lumbar pine

$\mathrm{CV}_{\mathrm{s}}=$ conduction velocity of the sciatic nerve and roots

$\mathrm{CL}_{8}=$ central latency, conduction time at the level of the brain and spinal cord

$\mathrm{CLI}_{\mathrm{s}}=\mathrm{CL}_{\mathrm{s}}$ compared to the body length (BI) of controls

A-P1/N1 = amplitude between peaks $\mathrm{P} 1$ and $\mathrm{N} 1$ of scalp response

$\mathbf{N}=$ number of controls 
Table 2 The measured and calculated values of Approach II

\begin{tabular}{|c|c|c|c|c|c|c|c|c|}
\hline & $\begin{array}{l}\text { lat } N o \\
(m s)\end{array}$ & $\begin{array}{l}\text { lat } \mathrm{No} / \mathrm{Bl} \\
(\mathrm{ms} / \mathrm{m})\end{array}$ & $\begin{array}{l}\text { lat } P_{1} \\
(m s)\end{array}$ & $\begin{array}{l}\text { lat } F \\
(m s)\end{array}$ & $\begin{array}{l}C T_{F} \\
(m s)\end{array}$ & $\begin{array}{l}C L_{F} \\
(m s)\end{array}$ & $\begin{array}{c}C L I_{F} \\
(m s / m)\end{array}$ & $\begin{array}{l}A-P_{1} / N_{1} \\
(\mu V)\end{array}$ \\
\hline $\begin{array}{l}\text { Mean } \\
\text { SD } \\
\mathbf{N}\end{array}$ & $\begin{array}{r}31 \cdot 9 \\
2 \cdot 2 \\
10\end{array}$ & $\begin{array}{r}18 \cdot 6 \\
1 \cdot 2 \\
10\end{array}$ & $\begin{array}{r}36 \cdot 9 \\
2 \cdot 4 \\
10\end{array}$ & $\begin{array}{c}51 \cdot 0 \\
6 \cdot 8 \\
10\end{array}$ & $\begin{array}{r}22 \cdot 6 \\
3 \cdot 2 \\
10\end{array}$ & $\begin{array}{l}9 \cdot 5 \\
2 \cdot 4 \\
10\end{array}$ & $\begin{array}{r}5 \cdot 8 \\
1 \cdot 6 \\
10\end{array}$ & $\begin{array}{l}2 \cdot 6 \\
1 \cdot 5 \\
10\end{array}$ \\
\hline
\end{tabular}

lat $\mathrm{No}=$ latency to the onset of scalp response

lat $\mathrm{No} / \mathrm{B} 1=$ lat No compared to the body length of controls

lat $P 1=$ latency to the peak $P 1$ of scalp response

$\mathrm{CT}_{\mathrm{F}}=$ conduction time of the tibial nerve and roots

lat $F=$ latency to the onset of the measured $F$-response

$C L_{F}=$ central latency conduction time at the level of the brain and spinal cord

$C L I_{F}=C L_{F}$ compared to the body length of controls

A-P1/N1 = amplitude between peaks $\mathrm{Pl}$ and $\mathrm{N} 1$

$\mathrm{N}=$ number of controls

Table 3 The measured and calculated values of Approach III

\begin{tabular}{|c|c|c|c|c|c|c|c|c|c|}
\hline & $\begin{array}{l}\text { lat No } \\
(m s)\end{array}$ & $\begin{array}{l}\text { lat } \mathrm{No} / \mathrm{Bl} \\
(\mathrm{ms} / \mathrm{m})\end{array}$ & $\begin{array}{l}\text { lat } P_{1} \\
(m s)\end{array}$ & $\begin{array}{l}\text { lat } H \\
(m s)\end{array}$ & $\begin{array}{l}C T_{I I} \\
(m s)\end{array}$ & $\begin{array}{l}C V_{H} \\
(\mathrm{~m} / \mathrm{s})\end{array}$ & $\begin{array}{l}C L_{H} \\
(m s)\end{array}$ & $\begin{array}{r}C L I_{I I} \\
(m s / m)\end{array}$ & $\begin{array}{l}A-P I / N I \\
(\mu V)\end{array}$ \\
\hline Mean & $25 \cdot 0$ & $14 \cdot 5$ & $29 \cdot 0$ & 28.9 & 11.9 & $58 \cdot 0$ & $13 \cdot 1$ & $7 \cdot 7$ & $1 \cdot 4$ \\
\hline SD & $2 \cdot 1$ & 1.0 & $3 \cdot 5$ & $2 \cdot 7$ & $1 \cdot 2$ & $3 \cdot 2$ & $1 \cdot 5$ & 0.8 & 0.7 \\
\hline $\mathrm{N}$ & 10 & 10 & 10 & 10 & 10 & 10 & 10 & 10 & 10 \\
\hline
\end{tabular}

lat No=latency to the onset of scalp response

lat $\mathrm{No} / \mathrm{Bl}=$ lat $\mathrm{No}$ compared to the body length (B1) of controls

lat $\mathrm{P} 1=$ latency to the peak of $\mathrm{P} 1$ of scalp response

$\mathrm{CT}_{\mathrm{H}}=$ conduction time of the sciatic nerve and roots

$\mathrm{CV}_{\mathrm{H}}=$ conduction velocity of sciatic nerve and roots

$C L_{\mathrm{H}}=$ central latency, conduction time at the level of the brain and spinal cord

$\mathrm{CLI}_{\mathrm{H}}=\mathrm{CL}_{\mathrm{H}}$ compared to the body length (Bl) of controls

A-P1/N1 = amplitude between peaks $\mathrm{P} 1$ and $\mathrm{N} 1$ of scalp response

lat $\mathrm{H}=$ latency to the onset of the maximal $\mathrm{H}$ response

$\mathrm{N}=$ number of controls

Case 1, the conduction velocity of the sciatic nerve, $\mathrm{CV}_{\mathrm{H}}$, was $48 \mathrm{~m} / \mathrm{s}$ on the right (the lesion side), a slightly abnormal value (differing more than 2 SD from the mean), and the corresponding $\mathrm{CV}_{\mathrm{H}}$ value on the left was $55 \mathrm{~m} / \mathrm{s}$ (normal). The responses from the scalp were not clearly distinguishable. The surface recordings from the second lumbar level induced with the stimulation of the tibial nerve (fig 4) were hardly detectable, but the recordings from the epidural space with platinum iridium wire electrode showed obvious responses (fig 5).

Case 2, the scalp recordings induced with the stimulation of the tibial nerve from the popliteal fossa showed no responses, but those produced by stimulation of the median nerves at the wrist showed obvious responses, as did recordings from the seventh cervical segment. Figure 6 shows the evoked responses at both levels induced by stimulation of the right median nerve. The $\mathrm{H}$ response was easy to detect on both sides and $\mathrm{CV}_{\mathbf{H}}$ was normal on the right $55 \mathrm{~m} / \mathrm{s}$ ), but slightly decreased on the left $(45 \mathrm{~m} / \mathrm{s})$.

Case 3, the $\mathrm{H}$ response was present on both sides and the $\mathrm{CV}_{\mathbf{H}}$ values were normal. The latency at the onset of the scalp response of the right hemi-

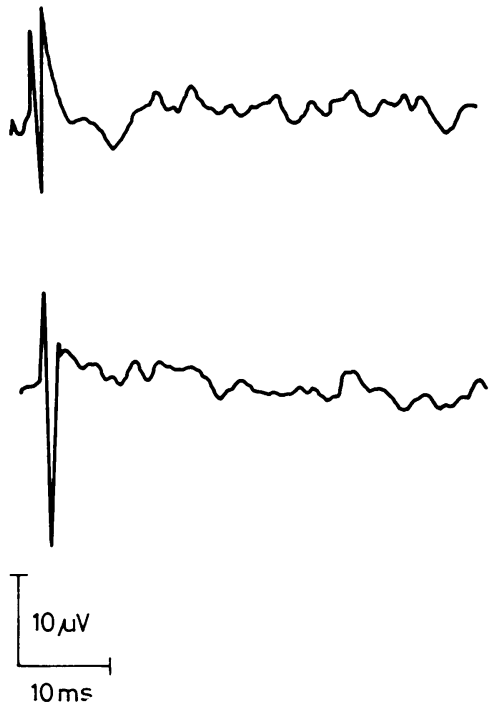

Fig 4 Case 1, with radicular lesion at the lumbosacral level. Upper tract: surface recording from the second lumbar spine induced by stimulation of the right tibial nerve in the popliteal fossa. Lower tract: surface recording from the second lumbar spine induced by stimulation of the left tibial nerve in the popliteal fossa (256 responses were averaged). 

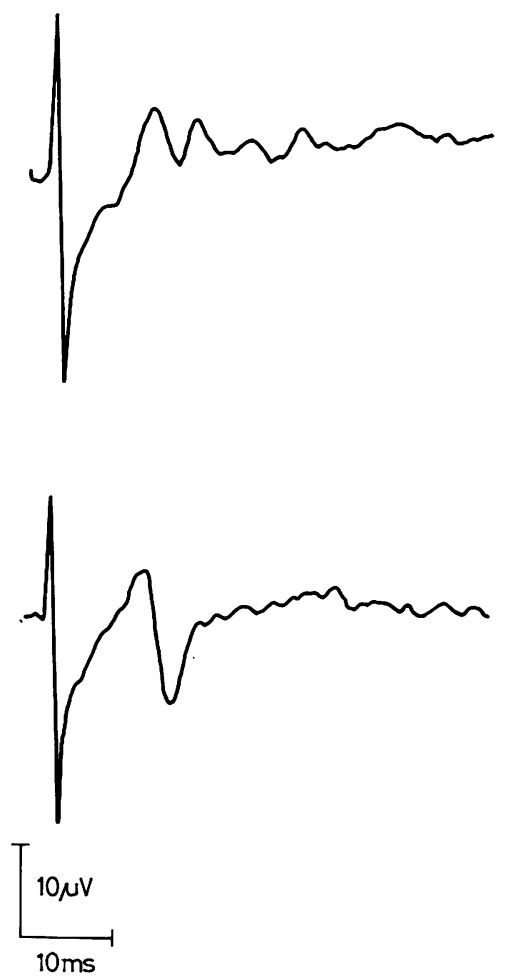

Fig 5 Case 1, with radicular lesion at the lumbosacral level. Upper tract: recording of response from the epidural space with platinum-iridium wire electrode at the level of the third lumbar segment induced by stimulation of the right tibial nerve in the popliteal fossa (reference in subcutaneous tissue, about five $\mathrm{cm}$ from cathode). Lower tract: stimulation of the left tibial nerve in the popliteal fossa; recording as above (256 responses were averaged).

sphere was abnormally prolonged (lat No was about $40 \mathrm{~ms}$, and $\mathrm{CL}_{\mathrm{H}} 27 \mathrm{~ms}$ ). The scalp response of the left hemisphere was dispersed and difficult to identify.

\section{Dissussion}

Somatosensory evoked potential recordings offer one method of measuring the conduction time of the central nervous system, brain and spinal cord. SSEPs, however, are much more difficult to record with surface electrodes from the thoracic or lumbar levels of the spinal cord than from the brachial plexus and cervical cord. $\mathrm{F}$ and $\mathrm{H}$ responses offer a non-invasive method of determining the conductivity of the lumbar roots and sciatic nerve.
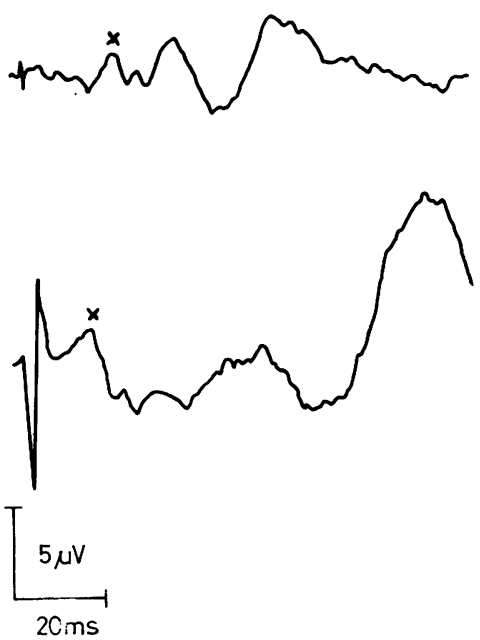

Fig 6 Case 2, with Hodgkin's disease. Upper tract: scalp response induced by stimulation of the right median nerve at the wrist. $\times$ shows the peak of the primary response of cortex peak-N20 (for details, see Siivola et al. ${ }^{23}$ Lower tract: response at the seventh cervical segment, recorded with surface electrodes between the sixth and seventh cervical spine, induced by stimulation of the right median nerve at the wrist. $\times$ shows the peak $N 13$, the top of the negative deflection of the response.
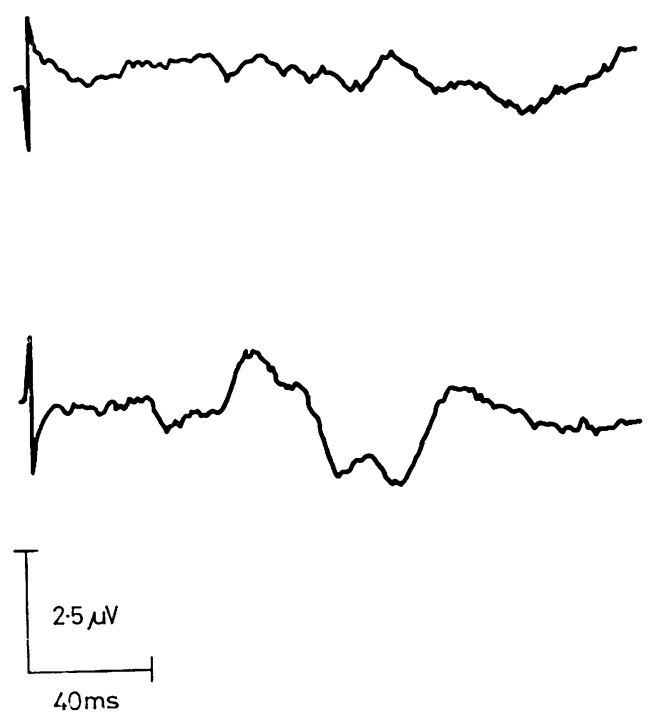

Fig 7 Case 3, with MS. Upper tract: scalp response induced by stimulation of the right tibial nerve in the popliteal fossa. Lower tract: scalp response induced by stimulation of the left tibial nerve in the popliteal fossa. 
In Apprcach $I$ the observed latency at the onset of scalp response (lat No, $29.2 \mathrm{~ms}$, and that at the peak P1 (lat $\mathrm{P} 1,33.4 \mathrm{~ms}$ ), are near reported values Larson et al ${ }^{24}$, Giblin ${ }^{25}$ and Tsumoto et al. ${ }^{2}$ The latency values No and P1 were calculated from the scalp recordings because they originate from the component I of the scalp response (see figs 1-3) which, it has been suggested, results from postsynaptic activation of the thalamocortical neural pathways. ${ }^{2}$ Component $I$ is the first cerebral manifestation in the scalp recording following the activation of the medial lemnisci tracts. The selection of the site of the recording electrode, about $2.5 \mathrm{~cm}$ behind from the vertex, is based on the investigations of Tsumoto $e t a l^{2}$, who found the component $\mathrm{I}$ to be maximal in this position. The conduction velocity of the sciatic nerve $(\mathrm{CV} s)$ in Approach $I$ is quite near the corresponding conduction velocity of the sciatic nerve, $\mathrm{CV}_{\mathrm{E}}$, in Approach III, but the central latency index (CLIs) is much higher than the respective values in Approaches II and III (CLIF and CLI ${ }_{H}$ ). This difference may be due partially to the different subjects, but this is unlikely to be the only cause. More study is needed to explain this point.

In Approach II the latency at the onset of scalp response $(31.9 \mathrm{~ms})$ corresponds well with the results reported by Jones and Small ${ }^{5}$ and Dorfman. ${ }^{4}$ The differences are even slighter if the results are correlated to body lengths (B1) of controls (lat $\mathrm{No} / \mathrm{B} 1$ ); the value of $18.6 \mathrm{msec} / \mathrm{m}$ in the present study compared with $17.6 \mathrm{~ms} / \mathrm{m}$ obtained by Dorfman and Bosley. ${ }^{26}$ The observed lat P1 $36.8 \mathrm{~ms}$ ) is about $3 \mathrm{~ms}$ less than reported by Jones, ${ }^{5}$ but that difference may be due to the differences in the body lengths of the controls. The latency of the $F$ response (lat $F)(51.0 \mathrm{~ms})$, is quite similar to the value reported by Dorfman. ${ }^{4}$ When calculating the $C_{F}$ values the scatter was large (SD $26 \%$ of the mean), while the distribution (expressed as SD) of $\mathrm{CL}_{\mathrm{II}}$ in Approach III was only $11 \%$ of the mean. This is probably because $\mathrm{H}$ response is easy to produce, and its latency and amplitude are much more stable than those of $F$ response, which in the present study changed very much even during the same experiment (see also Fra and Brignolio ${ }^{19}$ ). In Approach III lat No $(25.0 \mathrm{~ms})$ and lat P1 $(29.0 \mathrm{~ms})$ were in the same range as the findings reported by Delbeke et $a l^{6}$. The conduction velocity of the sciatic nerve and roots $\left(\mathrm{CV}_{\mathrm{H}}\right)(58 \mathrm{~m} / \mathrm{s})$, corresponds well with the values reported by Vecchierini-Blineau and Guiheneuc. ${ }^{20}$ The central latency values (CLs) and the corresponding central latency indexes in Approaches II and III, (CLIF and $\mathrm{CLI}_{\mathrm{H}}$ ) were, in theory, analogous values since they involved the same subjects. However, the values $\mathrm{CLF}_{\mathrm{F}}$ and $\mathrm{CL}_{\mathrm{r}}$ were statistically significantly different. This is due partially to the fact that the $F$ response only tests the efferent neural pathways, but the $\mathrm{H}$ response estimates the average conduction time in both the afferent and efferent neural pathways, and it is known that conduction velocity in afferent proprioceptive paths is faster than in efferent motor pathways. ${ }^{19}$

Measurements of the evoked potentials at the lumbar levels using surface electrodes seems io be of limited value. In persons with relatively thick back muscles and subcutaneous fat, it is only with great difficulty that responses may be recorded with surface electrodes, and if a patient has difficulty in relaxing his back muscles the signalnoise ratio is low. Since the responses with skin electrodes are scarcely detectable, the differentiation of lesions at the brain, cervical and thoracic levels of the spinal cord is difficult with only stimulation of the peroneal or tibial nerve without invasive intrathecal or epidural recording. ${ }^{15}$ Dorf$\operatorname{man}^{4}$ has resolved this problem as follows: the conduction time at the thoracic level may be calculated as the difference between the latency of the scalp response for tibial nerve stimulation and conduction time in the cervical spinal cord calculated from the scalp and cervical responses of the median nerve. This method makes it possible to calculate indirectly the conduction velocity of the thoracic cord; however, the scatter of individual conduction velocities with this method is quite large (SD $18 \%$ of the mean ${ }^{4}$ ). The method described in this paper is similar to that reported by Dorfman. ${ }^{4}$ In case 2 the conduction time of the cervical cord was evaluated from the scalp and cervical responses induced with the stimulation of the median nerve from the wrist; normal responses were found on the scalp and the seventh cervical segment, but the responses were lacking on the scalp after stimulation of the tibial nerve from popliteal fossa. These findings suggested a lesion site at the level of thoracic spinal cord. This was confirmed with myelography. In case 1 , the responses of the skin recordings frcm the level of the second lumbar spine were scarcely detectable, but the recordings with platinum iridium wire electrodes from the epidural space at the level of the third lumbar segment showed clear asymmetry of the responses. The configuration of the response induced by stimulation of the left tibial nerve was similar to that reported by Shimoji et al, ${ }^{9}$ but the response induced with stimulation of the right tibial nerve was a flat dispersed potential. The 
epidural recording technique is perhaps a good aid in cases where the skin recordings technique proves inadequate and it carries less risk of infection than the subdural technique.

Case 3, with MS showed scalp responses of prolonged conduction time (lat No) but in the periphery the $C V_{H}$ values from both sides were normal. This suggests a decreased conduction velocity in the central nervous system, but normal conduction velocity in peripheral nerves, a typical finding in MS reported by many investigators. ${ }^{27}$

The present results suggest that the evaluation of the neural conduction time in the brain and spinal cord is more difficult than that of the peripheral nervous system. The measurement of the evoked potentials from the lumbar levels, the $F$ response and $\mathrm{H}$ response, may overcome this problem. The $\mathrm{H}$ response method seems to be the best of these three; it is easy to perform even in persons with thick back muscles and subcutaneous fat; and statistically it is more stable than $F$ response recording. In radicular lesions however, the recording of the evoked potentials with wire electrodes from the epidural space may offer a useful diagnostic tool for clinical practice.

\section{References}

1 Liberson WT, Kim KC. Mapping evoked potentials elicited by stimulation of the median and peroneal nerves. Electroencephalogr Clin Neurophysiol 1963; 15:721.

2 Tsumoto $\mathrm{T}$, Hirose $\mathrm{N}$, Nonaka $\mathrm{S}$, Takahashi $\mathrm{M}$. Analysis of somatosensory evoked potentials to lateral popliteal nerve stimulation in man. Electroencephalogr Clin Neurophysiol 1972; 33:379-88.

3 Cracco RQ. Spinal evoked response: peripheral nerve stimulation in man. Electroencephalogr Clin Neurophysiol 1973; 35:379-86.

4 Dorfman LJ. Indirect estimation of spinal cord conduction velocity in man. Electroencephalogr Clin Neurophysiol 1977; 42:26-34.

5 Jones SJ, Small DG. Spinal and sub-cortical evoked poten'ials following stimulation of the posterior tib:al nerve in man. Electroencephalogr Clin Neurophysiol 1978; 44:299-306.

6 Delbeke J, McComas AJ, Kopec SJ. Analysis of evoked lumbocacral potentials in man. J Neurol, Neurosurg Psychiatry 1978; 41:293-302.

7 Dimitrijevic MR, Larsson LE, Lehmkuhl D, Sherwood A. Evoked spinal cord and nerve root potentials in humans using a non-invasive recording technique. Electroencephalogr Clin Neurophysiol 1978; 45:331-40.

8 Shimoji K, Higashi H, Kano T. Clinical and Laboratory Notes. Epidural recording of spinal electrogram in man. Electroencephalogr Clin Neurophysiol 1970; 30:236-39.
9 Shimoji K, Kano T, Higashi H, Morioka T, Henschel O. Evoked spinal electrograms recorded from epidural space in man. J Appl Physiol 1972; 4:468-71.

10 Caccia MR, Ubiali E, Andreussi L. Spinal evoked responses recorded from the epidural space in normal and diseased humans. J Neurol, Neurosurg Psychiatry 1976; 39:962-72.

11 Magladery JW, Porter WE, Park AM, Teasdall HD. Electrophysiological studies of nerve and reflex activity in normal man. IV. The two neuron reflex activity and identification of certain action potentials from spinal roots and cord. Bull Johns Hopk Hosp 1951; 88:499-519.

12 Ertekin C. Human Evoked Electrospinogram. In: Desmedt JE, ed New Developments in Electromyography and Clinical Neurophysiology. Basel: Karger, 1973; 2:344-51.

13 Ertekin C. Studies on the human evoked electrospinogram. II. The Conduction Velocity along the orsal Funiculus. Acta Neurol Scand 1976; 53:21-38.

14 Ertekin C. Studies on the human evoked electrospinogram. I. The Origin of the Segmental Evoked Potentials. Acta Neurol Scand 1976; 53:3-20.

15 Ertekin C. Comparison of the human evoked electrospinogram recorded from the intrathecal, epidural and cutaneous levels. Electroencephalogr Clin Neurophysiol 1978; 44:683-90.

16 Dawson GD, Merton PA. "Recurrent" discharges from mononeurones. In: 20th International Congress of Physiologists, Brussels: Abstracts of Communications 1956; 221-22.

17 McLeod JG, Wray SH. An experimental study of the $F$ wave in the baboon. $J$ Neurol Neurosurg Psychiatry 1966; 29:196-200.

18 Mayer RF and Feldman G. Observations on the nature of the $\mathrm{F}$ wave in man. Neurology (Minneap) 1967; 17:147-56.

19 Fra L, Brignolio F. F and H Responses elicited from Muscles of the Lower Limb in Normal Subjects. J Neurol Sci 1968; 7:251-61.

20 Vecchierini-Blineau MF, Guiheneuc P. Electrophysiological study of the peripheral nervous system in children. $J$ Neurol Neurosurg Psychiatry 1979; 42:753-59.

21 Skoglund S. On the postnatal development of postural mechanisms as revealed by electromyography and myography in decerebrate kittens. Acta Physiol Scand 1960; 49:299-317.

22 Guiheneuc P. Vitesse de conduction nerveuse motrice et réflexe de Hoffman. Thése Doctorat en Médecine, Nantes 1971.

23 Siivola J, Myllylä VV, Sulg I, Hokkanen E. Brachial plexus and radicular neurography in relation to cortical evoked responses. J Neurol Neurosurg Psychiatry 1979; 42:1151-58.

24 Larson SJ, Sances Jr A, Christenson PO. Evoked somatosensory potentials in man. Neurology (Minneap) 1966; 15:8-93. 
25 Giblin DR. Somatosensory evoked potentials in healthy subjects in patients with lesions of the nervous system. Ann NY Acad Sci 1964; 112: 93-142.

26 Dorfman LJ, Bosley TM. Age-related changes in peripheral and central nerve conduction in man.
Neurology (Minneap) 1979; 29:38-44.

27 Small DG, Matthews WB, Small M. The cervical somatosensory evoked potential (SEP) in the diagnosis of multiple sclerosis. J Neurol Sci 1978; 35:211-24. 